The notes on the dilferent plants supply the opportunities for considering accessory problems; thus the scarlet runner introduces twining, the marsh marigold leads up to a discourse on marsh plants, and so on. The volume concludes with a short epitome of ecological principles, while at the end of each chapter searching questions are proposed for solution. The author is to be congratulated on the excellent features of his book, which may be summarised as a clear diction, a logical sequence, and a recognition of the essentials.

The volume prepared by Mr. Percival Westell and Mr. Cooper does not present any very unique features. It is a systematic book containing a few coloured and numerous illustrations that are quite good, especially those in colour. A preliminary chapter furnishes hints on collecting, after which an explanation of general systematic and morphological terms leads to the enumeration of species. The salient distinctions of each order are given, and the specific characters are scheduled at the expense of much space. The book is somewhat simpler than a flora, but less complete, as only about 200 species are described.

\section{ELEMENTARY PHYSICS}

(1) First Year Physics. By Charles E. Jackson. Pp. viitri2. (London: Methuen and Co., n.d.) Price is. $6 d$.

(2) Einfiihrung in die Elektrochemie. By Prof. W. Bermbach. Pp. iv+r4o. (Leipzig: Quelle and Meyer, I907.)

(3) Magnetism and Electricity and the Principles of Electrical Measurement. By S. S. Richardson. Pp. viii +596 . (London: Blackie and Son, Ltd., 1908.) Price 5 s. net.

(1) THIS small manual is intended as a first-year text-book for schools where three or four hours per week are devoted to the subject. The book is divided into two portions; the first, theoretical, and consisting of about roo pages, deals with units of measurement, length, area, volume, density, pressure, and force. The second part consists of 76 laboratory exercises bearing on the subject-matter of the first portion. In addition, examples for home work are given at the ends of each chapter. The book is written in clear and simple language, and the illustrations are good. The section on "Mixtures," p. $5^{\mathrm{I}}$, is ill-chosen. A theoretical calculation of the density of a mixture as there indicated will most probably differ from that obtained practically by the pupil, owing to change in volume on mixing. Ágain, good practical results cannot be obtained from the pendulum experiments if carried out according to the directions indicated on $\mathrm{p}$. 85 , viz. :- -

"Allow the pendulum to swing through an arc of about 3 in. long and measure the time of ro complete swings, using a watch with a seconds' hand for this purpose. . . Repeat taking 20, 30, \&c., swings, and from each measurement calculate the time of one swing. The result in each case should be the same."

Again, in section 136 we are told to time 20 swings when investigating the variation of period with length, and as an example $\mathrm{r} .42 \mathrm{sec}$. is given as a period calculated from such an observation.

(2) The title of this book is somewhat misleading, as it does not deal with the applications of electrical methods to chemical industries, but is intended as an introduction to the study of physical chemistry. Although the treatment is of an elementary nature, the book may be profitably read by students of physics and chemistry. The first chapter is devoted by the author to a résumé of the laws and principles of electricity; the second chapter contains the fundamental conceptions and definitions on which the science of physical chemistry is based. The remainder of the book deals with such subjects as the electrolytic dissociation theory of Arrhenius, osmotic pressure, conductivity of electrolytes, migration of ions, and the theory of the voltaic cell. References to more advanced works on the subject are given at the end of the book.

(3) This text-book assumes a knowledge of the elementary descriptive portions of magnetism and electricity, and is intended for those students who are pursuing the subject further, either as a branch of pure physics or in preparation for a course of applied electricity. The author does not assume more than an elementary knowledge of the principles of trigonometry and mechanics in dealing with the subject. The treatment, on the whole, is very clear and concise, and the book contains considerably more matter than is usually found in books of this standard. Solutions of many questions set in recent examinations are included in the text, or given as examples to illustrate the subjectmatter. These will, no doubt, commend the book to many students preparing for examinations. The statement on p. 27, "When the lines of force are parallel the field is of uniform strength," is not a very intelligible way of defining a uniform magnetic field for an elementary student. Again, on p. 97, "If a conductor carrying an electric current is placed in a magnetic field it is subject to a mechanical force which depends on the length of the conductor, the current strength, and on a measure of the field," is a somewhat loose statement, there being no mention of the direction of the field with respect to the conductor. In Fig. 204, on p. 446, "Measurement of Thermoelectric Force," the connections are apparently wrong, although the author gives no explanation of the various parts of this figure.

\section{OUR BOOK SHELF.}

Text-book of Physiological Chemistry, in Thirty Lectures. By Emil Abderhalden. Translated by William 'T. Hall and George Defren. Pp. xiii +722 . (New York: John Wiley and Sons; London : Chapman and Hall, Ltd., 1908.) Price $21 s$. net.

WHEN Prof. Abderhalden's book was published in German about two years ago, its general excellence was at once noted, and it stepped immediately into the front rank of text-books which deal with this important and rapidly growing branch of physiology. Its author had already made for himself a great reputation as an original investigator, and as Prof. Emil Fischer's chief lieutenant had done much to elucidate the fundamental question which lies at the root of biochemistry, namely, the constitution of the protein molecule. In spite of

NO. 2044, VOL. 79] 